IZA DP No. 6356

The Labor Market Return to an Attractive Face:

Evidence from a Field Experiment

Florencia López Bóo

Martín A. Rossi

Sergio Urzúa

February 2012 


\title{
The Labor Market Return to an Attractive Face: Evidence from a Field Experiment
}

\author{
Florencia López Bóo \\ Inter-American Development Bank \\ and IZA \\ Martín A. Rossi \\ Universidad de San Andrés \\ Sergio Urzúa \\ University of Maryland, \\ University of Chile and IZA
}

\section{Discussion Paper No. 6356 \\ February 2012}

\author{
IZA \\ P.O. Box 7240 \\ 53072 Bonn \\ Germany \\ Phone: +49-228-3894-0 \\ Fax: +49-228-3894-180 \\ E-mail: iza@iza.org
}

\begin{abstract}
Any opinions expressed here are those of the author(s) and not those of IZA. Research published in this series may include views on policy, but the institute itself takes no institutional policy positions.

The Institute for the Study of Labor (IZA) in Bonn is a local and virtual international research center and a place of communication between science, politics and business. IZA is an independent nonprofit organization supported by Deutsche Post Foundation. The center is associated with the University of Bonn and offers a stimulating research environment through its international network, workshops and conferences, data service, project support, research visits and doctoral program. IZA engages in (i) original and internationally competitive research in all fields of labor economics, (ii) development of policy concepts, and (iii) dissemination of research results and concepts to the interested public.
\end{abstract}

IZA Discussion Papers often represent preliminary work and are circulated to encourage discussion. Citation of such a paper should account for its provisional character. A revised version may be available directly from the author. 
IZA Discussion Paper No. 6356

February 2012

\section{ABSTRACT \\ The Labor Market Return to an Attractive Face: Evidence from a Field Experiment ${ }^{*}$}

We provide new evidence on the link between beauty and hiring practices in the labor market. Specifically, we study if people with less attractive faces are less likely to be contacted after submitting a resume. Our empirical strategy is based on an experimental approach. We sent fictitious resumes with pictures of attractive and unattractive faces to real job openings in Buenos Aires, Argentina. We find that attractive people receive 36 percent more responses (callbacks) than unattractive people. Given the experimental design, this difference can be attributed to the exogenous manipulation of facial attractiveness of our fake job applicants.

JEL Classification: J71, J78

Keywords: facial attractiveness, callback rates, labor market discrimination

Corresponding author:

Florencia Lopez Boo

Inter-American Development Bank

1300 New York Avenue, N.W.

Washington, DC 20577

USA

E-mail: florencial@iadb.org

\footnotetext{
* We are grateful to Ernesto Dal Bó and Eduardo Cavallo for helpful comments and suggestions. Julián Aramburu and Iva Trako provided excellent research assistance. We acknowledge financial support from UBACyT (Universidad de Buenos Aires, Ciencia y Tecnología). Sergio Urzúa appreciates the support of Centro de Microdatos at the University of Chile through the Millennium Science Initiative sponsored by the Chilean Ministry of Economics, Development and Tourism, Project NS100041.
} 


\section{Introduction}

Several countries are currently analyzing the implementation of compulsory anonymous resumes that forbid candidates from including information such as a photograph, and/or their name, age, marital status, gender, and nationality, which could trigger discriminatory hiring practices. ${ }^{1}$ This initiative is a response to an increasing concern about job market discrimination against certain groups. Our paper contributes to these policy discussions by providing experimental evidence on the existence of discrimination based on physical appearance in an early stage of the job search process. Discrimination based on physical appearance is potentially important. For instance, in a randomly selected telephone survey in the US (Kuran and McCaffery, 2004), it was found that most of the participants felt that discrimination based on looks exceeded discrimination based on ethnicity or national background.

We conduct a randomized field experiment in Buenos Aires, Argentina. The common practice of attaching a photograph (a "head shot") to the resume explains our interest in this country. Although we analyze a different question, our experiment design follows the empirical strategy utilized in Bertrand and Mullainathan (2004). ${ }^{2}$ In particular, using recent research in psychology, anthropology, and graphic design technology, we first construct a series of fictitious faces and attach them to fictitious resumes. While we ensured that the resumes were of equal quality (we controlled for their content), we made the faces progressively more attractive or unattractive through manipulations by computer. Importantly, and unlike previous research, we based our analysis on validated definitions of attractiveness (Pallet, Link, and Lee 2010). We then submit these fictitious resumes (including photographs) to real job openings and analyze the responses (callbacks).

Our results indicate that attractive people receive 36 percent more callbacks than unattractive people. We also document that more attractive candidates are not only more likely to be contacted, but that they are contacted sooner than less attractive applicants. Given the experimental setting, the estimated beauty premia can only be attributed to the

\footnotetext{
${ }^{1}$ For France, see USA Today, December 6, 2004, "Anonymous resumes may fight discrimination in France.” For Germany, see Spiegel Online International, August 25, 2010, “German pilot project aims to reduce discrimination." For the United Kingdom, see The Guardian, January 1, 2010, "Call for anonymous CVs to stop job interview sexism and racism."

${ }^{2}$ See also the pioneer research by Daniel (1968), Jowell and Prescott-Clark (1970), and Riach and Rich (1987).
} 
differences in facial attractiveness of the job candidates. Our findings are robust to the inclusion of a comprehensive set of control variables and different model specifications.

Our article contributes to the large literature analyzing the importance of physical appearance on the labor market outcomes. It also fits with the growing literature showing that attractive people are believed to possess socially desirable traits. Indeed, Feingold's (1992) meta-analysis of this literature reports a robust association between physical attractiveness and many personality traits, social skills, mental health, and intelligence. $^{3}$

To our knowledge, this is the first study combining validated measures of attractiveness and an experimental design to analyze the link between beauty and the labor market.

\section{Related literature}

A relatively large body of empirical literature has analyzed the correlation between beauty and labor market outcomes (for a review of this literature, see Hamermesh, 2011). However, the evidence demonstrating a causal relationship is scarce.

Heilman and Saruwatari (1979) provide evidence of a positive correlation between beauty and labor market performance. Using data from a lab experiment, these authors find that while attractiveness is advantageous for men in managerial and clerical jobs, attractive women are favored only for clerical jobs. Biddle and Hamermesh (1994) provide further evidence of the beauty premium. Analyzing self-reported data on respondents' appearance and labor market variables, they find that unattractive people earn 5 to 10 percent less than average-looking people, who in turn earn less than the good-looking individuals. Interestingly, the effects for men are as large as those for women, and the impact of an individual's appearance is found to be mostly independent of occupation. In a related work, Harper (2000) study individuals born in Britain. He finds that the penalty of being unattractive (a self-reported measure) is about 15 percent lower wages for men and 11 percent lower wages for women as compared to the

\footnotetext{
${ }^{3}$ There is some evidence that beauty matters for social interaction, such as for marriage outcomes (Banerjee et al. 2009), online dating (Hitsch, Hortaçsu, and Ariely2010), and academic success (French et al. 2009). Consistent with the psychology literature, economists have also found that physical beauty elicits altruistic, trusting, and cooperative behavior in economic games (Solnick and Schweitzer 1999; Wilson and Eckel 2006; Andreoni and Petrie 2008; Eckel and Petrie 2011). However, in the theoretical economics literature, the observed beauty premium has been shown to be uncorrelated with the actions of attractive players (see Mobius and Rosenblat 2006, who show that productivity is unaffected by physical attractiveness).
} 
attractive applicants. In contrast to Hammermesh and Biddle (1994), Harper (2000) finds some evidence for occupation-specific effects, which may be attributed to either occupation-specific discrimination or to productivity effects (i.e., larger penalties are found for unattractive women working in clerical occupations). More recently, Fletcher (2009) uses longitudinal data on wages from the United States and finds that wage returns to (self-reported) attractiveness are large (5 to 10 percent) relative to the returns to ability (3 to 6 percent).

Most of the non-experimental evidence on a beauty premium comes from the United States and the United Kingdom. An exception is the study by Sanhueza, Bravo, and Giusti (2006), which uses survey data from Chile. Using a ranking committee to measure attractiveness, they find that the beauty premium in wages vanishes after few years in the labor market.

The works cited are all non-experimental studies. The identification of a causal link between attractiveness and labor market performance is a complex task: one that becomes particularly questionable in non-experimental settings. Different sources of biases, ranging from the selection into occupations/labor market to the potential reverse causality from income to attractiveness, might contaminate the results obtained from non-experimental settings (Bertrand and Mullainathan 2004).

Most of experimental studies use (imaginary) screening processes. ${ }^{4}$ Using a sample of real managers in financial institutions, Marlowe, Schneider, and Carnot (1996) find attractiveness and gender biases, where the extent of the bias is generally smaller for the most experienced managers. Watkins and Johnston (2000) find that attractiveness is an advantage for females, but only when the application was of a mediocre quality.

Our paper contributes to the literature by conducting a randomized field experiment in Buenos Aires, where we sent resumes of fictitious and equally qualified candidates to real job openings. Importantly, the resumes included fictitious photographs of our fake candidates' faces, manipulated to modify their levels of attractiveness. This strategy ensures that individual's differences in marginal productivities (productive

\footnotetext{
${ }^{4}$ In this type of strategy, the experimental participants are real supervisors and managers. Their task is to evaluate the resumes/data sheets of a subset of job applicants, all of which have a candidate photograph attached. All candidates have the same level of qualifications. Participants then judge the likelihood with which they would offer an interview to the applicant, the quality of the application, and the likely starting salary they would offer the applicant.
} 
endowments) are controlled for, and isolates the recruiter's judgment about the applicant's attractiveness.

The closest empirical study to ours is Ruffle and Shtudiner (2010). ${ }^{5}$ These authors analyze the effects of attractiveness on callback rates following a similar experimental strategy to ours but in Israel. However, on methodological grounds, our approach differs from that of Ruffle and Shtudiner (2010) in an important dimension: how we measure beauty. Indeed, previous papers analyzing beauty or attractiveness have used subjective measures of beauty to rank physical appearance. In particular, Ruffle and Shtudiner (2010) use a ranking of photographs, which is the result of the subjective assessments of the authors, their (female) assistants and eight judges (4 males and 4 females with different professional backgrounds including economists, hair stylists, and public relations). By definition, subjective measures of beauty can be influenced by culture, idiosyncratic perceptions (potentially influenced by age, race, gender, education, etc), and even cross-cultural interactions, which could limit the scope and interpretation of the resulting findings.

In this paper we follow an alternative approach, which avoids the previous concerns. Specifically, we use the latest psychology and anthropology research to build what from a scientific perspective could be defined as attractive and unattractive faces (see section III). Importantly, our results demonstrate the validity of these objective measures.

To sum up, our paper contributes to the literature by combining a rigorous methodology (a randomized field experiment) with a state-of-the-art validated measure of beauty, which goes beyond the subjective and culture-influenced concepts of attractiveness commonly used in previous studies. This allows us to assess the effects of beauty on labor market outcomes, as measured by callback rates.

\section{The experiment}

Our experiment focuses on facial attractiveness. We follow Budge (1981), who argues that the face is the most important component of a person's physical attractiveness. In this context, Argentina provides an ideal setting for the analysis of the relationship between physical (facial) attractiveness and the hiring practices of the labor

\footnotetext{
${ }^{5}$ Rooth (2009) finds strong indications of discrimination against obese workers by measuring employer callbacks for fictitious job applications to real jobs, where pictures of an obese or non-obese person were randomly assigned to similar applications. However, obesity and facial attractiveness are very different "treatments," since an individual's own weight, or at least the control of an individual's own weight, is a personal trait (Offer 2001).
} 
market. For decades, attaching facial photographs to resumes has been a standard practice among Argentineans. Even though attaching a facial picture is in general not mandatory, applicants are always given the possibility of including a picture. Moreover, based on what is specified in Human Resources websites that give advice for the construction of resumes, including a picture is neither a positive nor a negative signaling for recruiter. ${ }^{6}$

Thus, we tackle our question of interest by randomly attaching professionally manipulated portrait photographs to fictitious resumes. The experiment was carried out between April 21 and June 20, 2010, in Buenos Aires, Argentina. During this period, on average, we electronically submitted 60 fictitious resumes per day in response to real employments ads published in the most important job search website in Argentina. We ended up submitting 2,540 applications.

\section{Generating the resumes}

In order to produce realistic and representative resumes, the first step of our experimental design was to download around 200 publically available resumes from a popular job search website in Argentina. ${ }^{7}$ Based on the format and structure of these resumes, we constructed a set of fictitious resumes that were filled out with fictitious names, ages, and addresses.

We restricted the analysis to individuals seeking employment in Buenos Aires, holding at least a high school degree, and who were searching for a job in one of the following occupational categories: sales-commercial, administrative-accountancy, marketing-advertisement, secretaries-receptionists-customer service, gastronomy, and general unskilled positions (such as cleaning and maintenance, clerical work, and technicians). ${ }^{8}$

We concentrated our analysis on two age groups, 20 to 23, and 26 to 27 years old. The names and surnames used in the experiment were obtained from a list of the most common names and surnames in Argentina. ${ }^{9}$ In addition, to each of the fictitious names, we attached a national identification (ID) number. Importantly, Argentina uses a strict

\footnotetext{
${ }^{6}$ See http://opinionsur.org.ar/joven/Como-armar-un-curriculum.

${ }^{7}$ We restricted the analysis to individuals with high school degrees, post-secondary technical degrees (also known as "terciario" degrees in Argentina), and college graduates. The vast majority of the ads in the job-search website require at least a high school degree.

${ }^{8}$ We selected these occupations because they represent a large number of job openings, representing 56 percent of the total ads.

${ }^{9}$ See Silvana Herrera, "El origen y la historia de los apellidos en Argentina," Diario Perfil, March 19, 2008.
} 
continuous numeration of ID numbers; as a result, ID numbers are linked to the age of their owners. This prevented us from using fictitious IDs in our study. We overcame this by utilizing real ID numbers from a group of twelve individuals who signed a written consent authorizing the use of their ID numbers. We selected this group so that six of its members were 20-23 years old and six were aged 26-27. Once we concluded the process of generating names (and IDs), we set up email accounts consistent with our list of names. We generated one email address per fictitious applicant. We used the common domains: hotmail.com, gmail.com, and yahoo.com. The marital status of our 20-23year-old fictitious applicants was set to single, while those aged 26-27 were randomly assigned single or married status. ${ }^{10}$ We also randomly assigned fake addresses to the resumes.

With respect to the human capital of the fictitious candidates, we randomly assigned one of three schooling levels: high school degree, post-secondary technical degree, or college degree. ${ }^{11}$ For those with post-secondary education, we listed the name of a university. These names were selected so that they best complied with the educational requirements of the vacancy. For those with a high school degree, we listed the name of a high school selected according to the applicant's neighborhood of residence. A bank of public high schools was constructed for this purpose. Using the official websites of the City of Buenos Aires and the Ministry of Education, we randomly selected public schools for each of the 15 neighborhoods of Buenos Aires. Finally, those with post-secondary education were assumed to be proficient in English, while those with high school degrees were assumed to have basic knowledge of English.

\section{Generating the photographs}

We based our identification strategy on the following typography: resumes of attractive individuals (males/females); resumes of unattractive individuals (males/females); and resumes without facial photographs (males/females). This yielded six types of resumes (three for each gender).

To construct the photographs, we first took pictures of 50 real men and 50 real women, between the ages of 20 and 30. The 100 photos were taken at Universidad de Buenos Aires. Each photographed person (all of them college students) signed a

\footnotetext{
${ }^{10}$ We took into account the fact that, in Argentina, marriage usually does not occur before age 25 for both males and females.

${ }^{11}$ In the U.S. context, post-secondary technical degrees are equivalent to a two-year college degree, whereas a college degree represents a four-year degree.
} 
standard photograph authorization form. The images were then manipulated by a professional graphic designer, who transformed the real photos into fictitious ones by randomly mixing up pairs of real pictures (i.e. she took two pictures at random from the pool of 100 photos, and then mixed them up using the Morph Age Pro software -see details in Appendix 1). This process yielded 25 new photos of fictitious individuals: 13 women and 12 men.

Our measure of facial attractiveness is based on Pallet, Link, and Lee (2010). These authors constructed what has been interpreted in the literature as the first "validated" measure of facial beauty-not subject to an ad hoc committee. In their study, each participant makes paired comparisons of attractiveness across pictures of women faces that have identical facial features (eyes, noses, mouths, and so on) but different distances between the eye and mouth (eye-mouth distances) and different distances between the eyes (inter-ocular distances). Pallet, Link, and Lee (2010) find that facial attractiveness is optimized when the vertical distance between the eyes (i.e. the middle point of the horizontal distance between the pupils) and the mouth (i.e. the central point of the oral commissure, just under the philtrum) is approximately 36 percent of its length (i.e. the distance between the hairline and the chin), and the horizontal distance between the eyes (i.e., the pupils) is approximately 46 percent of the face's width (i.e., the distance between the inner edges of the ears). These new "golden ratios" match those of an average face. These are the proportions we used for our pictures of attractive job applicants. ${ }^{12}$

Likewise, we constructed unattractive faces by varying these two distances. In particular, we generated unattractive applicants by moving the two distances away from the golden ratios. ${ }^{13}$ To keep the faces credible, we modified each face based on its own features, but always moving its proportions away from the golden ratios. Table A1 in Appendix 1 presents an example of this process (see the Appendix for more details on the construction of the pictures). Table A2 in Appendix 1 presents the mean, interval,

\footnotetext{
${ }^{12}$ The face from which the attractive and unattractive pictures were created was itself the result of the blending of two (real) photos, and therefore distance ratios of that composite picture were not far from the more attractive population average. Thus, those pictures were barely modified, which means that ratios are not exactly like the golden ratios, but close enough to them (see Table A2).

${ }^{13}$ We made this decision following Jones (1995), who finds that for both males and females, faces subjected to positive cardioidal strain (more distance) were rated consistently less attractive than original faces, while results for faces subjected to negative cardioidal strain (less distance) were less conclusive. This implies that as Pallet, Link and Lee have a width ratio scale that goes from 0.35 to 0.52 (less distance to more distance), our ratio goes from 0.45 to 0.62 (from the average face to more distance). The same happens with the length ratio.
} 
and standard deviations of the two ratios for the full sample, the attractive candidates, and the unattractive candidates. ${ }^{14}$

Final steps

We eliminated those vacancies (employment ads) in which applicants were asked to call or appear in person. For each of the remaining vacancies, we used the bank of resumes to sample six resumes that fit the job description and requirements as closely as possible. We placed three resumes of males and three resumes of females in our sample. Within each gender we selected one resume of an attractive candidate, one of an unattractive candidate, and one resume without a photograph.

As explained, each set of six resumes was constructed so that qualification levels were equivalent in such a way that the applicants were equally eligible for the job. In some cases, we slightly altered the resumes to improve the quality of the match, such as by adding the knowledge of a specific software program or experience in a particular field.

The final set of six resumes with its corresponding pictures was then uploaded in the job search engine, where all resumes have the same template and format. Through this job search engine, when the candidate applies for a job, the same website sends the resume to the employers on behalf of the job seeker. Importantly, each resume of the set of six had a unique telephone number, which allowed us to track employer callbacks precisely. We used six mobile phones to ensure that recruiters did not receive repeated phone numbers.

\section{Econometric model and results}

Table 1 presents the descriptive statistics of our sample. In most cases, the characteristics of the applicants are not associated with facial attractiveness (or the presence of a photo in the resume). Only marital status is unbalanced between attractive applicants and applicants that did not attach a picture. This is due to the fact that marital status was assigned based on the age of the applicant (see Section III). Still, results are robust to controlling for marital status (see Table 3). This confirms the validity of our experimental design. ${ }^{15}$

\footnotetext{
${ }^{14}$ Additionally, the web appendix (available from the authors upon requests) contains the values of the different ratios for each of the faces.

${ }^{15}$ Note that our design balances the variable Age Group (a dummy variable that takes the value of one for candidates aged 20 to 23 years old and zero for candidates aged 26 or 27 years old). As shown in Tables 3 and 4 , results are robust to controlling for age.
} 
We are interested in estimating the causal effect of facial attractiveness on callback rates. Formally, we estimate the following equation:

$$
\text { Callback }^{i}=\alpha+\beta \text { Attractive }{ }^{i}+\varphi X^{i}+\varepsilon^{i},
$$

where $i$ indexes resumes; Callback is a dummy variable that takes the value of one when the fictitious applicant is contacted (she/he receives a callback) and zero otherwise; Attractive is a dummy variable that takes the value of one for resumes that include a photograph of an attractive applicant and zero otherwise; $X$ is the set of control variables that includes whether or not a photograph is attached to the resume; and $\varepsilon$ is an error term. The main parameter of interest is $\beta$. Given the random assignment, Equation 1 can be estimated straightforwardly by Ordinary Least Squares.

Table 2 reports the average callback rates by category of facial attractiveness. Resumes with a photograph of an attractive applicant have a 10.3 percent chance of receiving a callback. Equivalent resumes with a photograph of an unattractive applicant have a 7.6 percent chance of being called back for an interview. This represents a difference in callback rates of 2.7 percentage points (or 36 percent) that given our experimental design can only be attributed to manipulation of the facial attractiveness of the candidates. The difference in callback rates is statistically significant at the 5 percent level. Resumes without a photograph attached have callback rates of 7.9 percent.

Table 3 reports the results of OLS regressions of Equation 1. In column 1, we restrict the sample to those resumes with a photograph attached. In column 2, we include all resumes. In column 3, we control for the following characteristics: Age; Male (a dummy variable that takes the value of one for men); Married (a dummy variable that takes the value of one for married applicants); and Photo Required (a dummy variable that takes a value of one if the job advertisement required a photograph to be attached to the resume). In all cases, the estimated coefficient on Attractive is positive and significant, indicating the presence of a beauty premium. To further explore if the beauty premium is different for men and women, in column 4 we include an interaction term between Attractive and Male. The estimated coefficient associated with the interaction term is not significant, suggesting that the beauty premium is similar for women and men. This contradicts the evidence in Ruffle and Shtudiner (2010) suggesting that only men enjoy a beauty premium, and subsequently, it challenges their explanation, namely that female jealously of attractive women in the workplace explains the punishment of attractive women. On the contrary, we interpret the different results 
as suggestive of the importance of using objective versus subjective measures of beauty. (An alternative explanation would be cultural or institutional differences between Israel and Argentina, which we consider less plausible).

Our result of a significant beauty premium survives a battery of robustness checks. Similar results are obtained after allowing for the interaction of Attractive and different exogenous controls. ${ }^{16}$ Likewise, the results are unaffected by the inclusion of rich set of controls such as hair color, skin color, schooling dummies, vacancy name dummies, and even firm dummies (fixed effects). ${ }^{17}$

In order to explore the importance of the type of occupation on the beauty premium, we estimate the model for each of the six occupational categories available in our data: Sales and related occupations, office and administrative support occupations (excluding secretaries, receptionists and customer services), office and administrative support (secretaries, receptionists, and customer service), business and financial operations (marketing specialists, management analysts), food preparation and serving related occupations (waiters and waitresses, food servers, cooks, chefs), and other general unskilled positions. ${ }^{18}$ Table 4 presents the results. For each occupation we present the results excluding (columns (A)) and including (columns (B)) the interaction of Attractive and gender (male). In this way, we revisit the hypothesis of genderspecific beauty premium but this time by occupation.

The results in columns (A) show that the estimated coefficient on Attractive is significant for two out of the six occupational categories. Importantly, the results are particularly relevant for occupations requiring an interaction with customers. The beauty premium is 0.043 for food preparation and serving related occupations (column $4 \mathrm{~A})^{19}$, and 0.075 for office and administrative support including secretaries, receptionists and general customer service (column 5A). Columns (B) confirm these findings, with estimated beauty premium 0.109 (column 4B) and 0.067 (column 5B), for office and administrative support and food preparation and serving related occupations, respectively. However, our findings also show the existence of a beauty

\footnotetext{
${ }^{16}$ In a set of results not included in the paper, we allow for the interactions of Attractive and marital status, Attractive and photo required, and Attractive and age. The results confirm that the interactions are not statistically significant. Results are available from the authors upon request.

${ }^{17}$ The set of results from the different robustness checks are available from the authors upon request.

${ }^{18}$ The classification of occupational categories follows the Standard Occupational Classification (SOC) (see www.bls.gov/soc/ for further details).

19 In the case of the food preparation and serving related occupations, $38 \%$ corresponds to waiters/waitresses and food servers, $50 \%$ to cooks and chefs, and $12 \%$ to other serving related jobs.
} 
premium for females submitting resumes to occupations as secretaries, receptionists and general customer service.

The previous results have analyzed the impact of beauty on callbacks using a binary variable. However, from our experimental design, we can incorporate our two objective measures of beauty as controls: the length ratio (the vertical distances between eyes and mouth as a fraction of the total face length), and the width ratio (the interocular distance as a fraction of the total face width). Table 5 reports our results. For a better interpretation of the estimates, we utilize the variables in logs instead of levels. ${ }^{20}$ This evidence confirms our previous findings. Both ratios explain the probability of receiving a callback. The estimates for the length ratio are -0.283 and -0.126 depending on whether or not we control for the width ratio. For the width ratio the estimates are 0.1703 (excluding length ratio) and -0.117 (including length ratio). This means that a 10 percent increase away in any of the ratios is associated with a reduction of (at least) one full percentage points in the probability of receiving a callback (or a 12 percent lower callback rate).

Finally, since we know when each of the resumes is submitted and when it elicits a callback (if there is a callback) we can also estimate a duration model (survival model) for the analysis of the responsiveness to attractive faces. Figure 1 depicts the nonparametric survivor function associated with attractive and unattractive applicants. This figure clearly shows how attractive candidates are not only more likely to be contacted, but also they are contacted sooner than unattractive applicants. We supplement this graphical representation of the differences in survivor functions with formal regression survival-time models. In this case, the dependent variable is "time until contact”. Table 6 presents the results (hazard-ratios) associated with different regression survival-time models. The structure of the table follows the one used in Table 2. The results confirm that more attractive candidates are not only more likely to be contacted, but that they are contacted sooner than less attractive applicants, even after controlling for observable characteristics. Specifically, column (3) suggests that individuals with attractive faces have a hazard of failure (the inverse of expected duration) almost 30\% larger than those with unattractive faces.

\footnotetext{
20 The signs and significance of our estimates do not depend on whether the variables are utilized in levels or logs.
} 


\section{Conclusion}

Using a field experiment based on real job openings in Argentina, we find evidence of the existence of a beauty premium at the early stages of job search. Our main finding is that attractive people receive 36 percent more callbacks for interviews than unattractive people. Previous experimental research indicates that beauty is not correlated with labor productivity (Mobius and Rosenblat, 2006). ${ }^{21}$ If this is the case, our finding suggests the existence of labor market discrimination against the less attractive.

From the perspective of job applicants, our results suggest that attractive candidates should attach a photograph to their resumes when given the opportunity to do so, since including a photograph increases the probability that they will be called for an interview by about 30 percent. Unattractive candidates, on the other hand, should not attach a photograph to their resumes because including a photograph decreases the probability of receiving a callback by about 5 percent. We do not find evidence of effects in the case of not attaching a photograph. We also document that more attractive candidates are not only more likely to be contacted, but that they are contacted sooner than less attractive applicants. Importantly, when we analyze potential channels driving the beauty premium we show that the results are particularly relevant (sizeable and significant) for occupations requiring the interaction with customers (serving related occupations and administrative support such as secretaries, receptionists and general customer service). Our findings also show the existence of a beauty premium for females submitting resumes to positions such as secretaries, receptionists and general customer service.

\footnotetext{
${ }^{21}$ Moreover, the only extreme cases of mental differences associated with different facial structures are those of the Down syndrome individuals, which are not included in our sample of pictures.
} 


\section{References}

Andreoni James, and Ragan Petrie. 2008. "Beauty, Gender and Stereotypes: Evidence from Laboratory Experiments.” Journal of Economic Psychology 29 (1): 7393.

Banerjee, Abhijit, Esther Duflo, Maitreesh Ghatak, and Jeanne Lafortune. 2009. "Marry for What? Caste and Mate Selection in Modern India”, CEPR Discussion Papers 7300, C.E.P.R. Discussion Papers.

Bertrand, Marianne and Sendhil Mullainathan. 2004. “Are Emily and Greg More Employable than Lakisha and Jamal? A Field Experiment on Labor Market Discrimination.” American Economic Review 94 (4): 991-1013.

Biddle, Jeff and Daniel Hamermesh. 1994. "Beauty and the Labor Market." American Economic Review 84 (5): 1174-94.

Budge, H. 1981. "Dimensions of Physical Attractiveness.” Unpublished doctoral dissertation. Salt Lake City: University of Utah.

Daniel, William. 1968. Racial Discrimination in England. Middlesex: Penguin Bools.

Eckel, Catherine and Ragan Petrie. 2011. "Face Value.” American Economic Review 101 (4): 1497-1513 .

Feingold, Alan. 1992. "Good-looking People Are Not What We Think." Psychological Bulletin 111 (2): 304-41.

Fletcher, Jason. 2009. “Beauty vs. Brains: Early Labor Market Outcomes of High School Graduates.” Economics Letters 105 (3): 321-25.

French, Michael, Philip Robins, Jenny Homer, and Lauren Tapsell. 2009. “Effects of Physical Attractiveness, Personality, and Grooming on Academic Performance in High School.” Journal of Labor Economics 16 (4): 373-382.

Hamermesh, Daniel. 2011. Beauty Pays. Why Attractive People are more Successful? Princeton University Press (Princeton and Oxford)

Harper, Barry. 2000. “Beauty, Stature, and the Labour Market: A British Cohort Study.” Oxford Bulletin of Economics and Statistics 62: 771-800.

Heilman, Madeline and Lois Saruwatari. 1979. "When Beauty is Beastly: The Effect of Appearance and Sex on Evaluations of Job Applicants for Managerial and Nonmanagerial Jobs.” Organizational Performance and Human Behavior 23 (3): 36072. 
Hitsch, Gunter, Ali Hortaçsu, and Dan Ariely. 2010 "Matching and Sorting in Online Dating.” American Economic Review 100 (1): 130-63.

Jones, Doug. 1995. "Sexual Selection, Physical Attractiveness and Facial Neoteny: Cross-cultural Evidence and Implications.” Current Anthropology 36 (5): 724 48.

Jowell, Roger and Patricia Prescott-Clarke. 1970. "Racial discrimination and white-collar workers in Britain.” Race 11: 397-417.

Kura, Timur and Edward Mc Caffery . 2004 "Expanding Discrimination Research: Beyond Ethnicity and to the Web.” Social Science Quarterly 85: 713-30

Marlowe, Cynthia, Sandra Schneider, and Nelson Carnot. 1996. “Gender and Attractiveness Biases in Hiring Decisions: Are More Experienced Managers Less Biased?” Journal of Applied Psychology 81 (1): 11-21.

Mobius, Markus and Tanya Rosenblat. 2006. “Why Beauty Matters.” American Economic Review 96 (1): 222-35.

Offer, Avner. 2001. "Body Weight and Self-control in the United States and Britain since the 1950s.” Social History of Medicine 14: 79-106.

Pallet, Pamela, Stephen Link, and Kang Lee. 2010. “New Golden Ratios for Facial Beauty.” Vision Research 50 (2): 149-154.

Riach, Peter and Judith Rich. 1987. "Testing for Sexual Discrimination in the Labor Market.” Australian Economic Papers 23: 165-178.

Rooth, Dan-Olof. 2009. “Obesity, Attractiveness, and Differential Treatment in Hiring: A Field Experiment.” Journal of Human Resources 44 (3): 710-35.

Ruffle, Bradley and Ze'ev Shtudiner. 2010. “Are Good-looking People More Employable?” Monaster Center for Economic Research and Ben-Gurion University of the Negev. Discussion Paper No. 10-06.

Sanhueza, Claudia, David Bravo, and Oscar Giusti. 2006. “La Belleza y su Efecto en el Mercado Laboral: Evidencia para Chile.” Unpublished.

Solnick, Sara and Maurice Schweitzer. 1999. "The Influence of Physical Attractiveness and Gender on Ultimatum Game Decisions.” Organizational Behavior and Human Decision Processes 79: 199-221.

Watkins, Lucy and Lucy Johnston. 2000. “Screening Job Applicants: The Impact of Physical Attractiveness and Application Quality.” International Journal of Selection and Assessment 8 (2): 76-84. 
Wilson, Rick and Catherine Eckel. 2006. “Judging a Book by its Cover: Beauty and Expectations in the Trust Game.” Political Research Quarterly 59 (2): 189-202. 
Table 1. Mean differences in exogenous variables by type of resume

\begin{tabular}{lcccccc}
\hline \multicolumn{1}{c}{ Variable } & Attractive & Unattractive & No Photo & Test: & Test: & Test: \\
& $(1)$ & $(2)$ & $(3)$ & H0: $(1)=(2)$ & H0: $(1)=(3)$ & H0: $(2)=(3)$ \\
\hline Age Group & 0.600 & 0.600 & 0.599 & $\{1.00\}$ & $\{0.98\}$ & $\{0.98\}$ \\
Male & 0.498 & 0.498 & 0.499 & $\{1.00\}$ & $\{0.98\}$ & $\{0.98\}$ \\
Married & 0.189 & 0.177 & 0.149 & $\{0.53\}$ & $\{0.03\}$ & $\{0.12\}$ \\
\hline Observations & 847 & 847 & 846 & 1694 & 1693 & 1693
\end{tabular}

Notes: p-values are shown in braces. Age Group is a dummy variable that takes the value of 1 for candidates aged 20 to 23 years old and 0 for candidates aged 26 or 27 years old; Male is a dummy variable that takes the value of 1 for men; Married is a dummy variable that takes the value of 1 for married applicants. 
Table 2. Callback rates by category of facial attractiveness

\begin{tabular}{l|c}
\hline Category of facial attractiveness & Mean callback \\
\hline Attractive & 0.103 \\
& $(0.304)$ \\
Unattractive & 0.076 \\
& $(0.264)$ \\
\hline Difference: Attractive - Unattractive & 0.027 \\
& $(0.014)$ \\
\{p-value & $\{0.050\}$ \\
\hline No Photo & 0.079 \\
& $(0.270)$ \\
\hline Overall & 0.085 \\
\end{tabular}

Note: Standard deviations in parentheses. 
Table 3. Main results

\begin{tabular}{l|cccc}
\hline \multirow{2}{*}{ Attractive } & $(1)$ & $(2)$ & $(3)$ & $(4)$ \\
& $0.027^{* * *}$ & $0.027^{* * *}$ & $0.022^{* * *}$ & 0.016 \\
No Photo & $(0.007)$ & $(0.007)$ & $(0.008)$ & $(0.011)$ \\
& & 0.004 & 0.003 & \\
\hline Attractive $x$ & & $(0.009)$ & $(0.009)$ & 0.009 \\
Male & & & & $(0.012)$ \\
\hline Constant & & & -0.070 & -0.069 \\
& & & $(0.091)$ & $(0.092)$ \\
\hline Controls & $(0.011)$ & $(0.011)$ & Yes & Yes \\
Observations & No & No & 2539 & 2539 \\
\hline
\end{tabular}

Notes: Standard errors clustered at the employer level in parentheses (462 clusters). All models are estimated by OLS. Controls include Age, Male, Married, and Photo Required. *, **, and *** denote the 10, 5 , and 1 percent significance level, respectively. 
Table 4. Results by occupational category

\begin{tabular}{|c|c|c|c|c|c|c|c|c|c|c|c|c|}
\hline & \multicolumn{12}{|c|}{ Dependent variable: Callback } \\
\hline & \multirow{2}{*}{\multicolumn{2}{|c|}{$\begin{array}{l}\text { (1) } \\
\text { ales and } \\
\text { Related } \\
\text { cupations } \\
\text { ncluding } \\
\text { onstrators) }\end{array}$}} & \multirow{2}{*}{\multicolumn{2}{|c|}{$\begin{array}{c}\text { (2) } \\
\text { Office and } \\
\text { Administrative } \\
\text { Support } \\
\text { Occupations } \\
\text { (excluding } \\
\text { secretaries, } \\
\text { receptionists and } \\
\text { customer } \\
\text { services) }\end{array}$}} & \multirow{2}{*}{\multicolumn{2}{|c|}{$\begin{array}{c}\text { (3) } \\
\text { Business and } \\
\text { Financial } \\
\text { Operations } \\
\text { Occupations } \\
\text { (Marketing } \\
\text { specialists, } \\
\text { management } \\
\text { analysts, } \\
\text { account } \\
\text { executive) }\end{array}$}} & \multirow{2}{*}{\multicolumn{2}{|c|}{$\begin{array}{c}\text { (4) } \\
\text { Office and } \\
\text { Administrative } \\
\text { Support } \\
\text { Occupations } \\
\text { (Secretaries- } \\
\text { Receptionists- } \\
\text { Customer } \\
\text { service) }\end{array}$}} & \multirow{2}{*}{\multicolumn{2}{|c|}{$\begin{array}{c}\text { (5) } \\
\text { Food } \\
\text { Preparation and } \\
\text { Serving Related } \\
\text { Occupations } \\
\text { (Waiters and } \\
\text { Waitresses, } \\
\text { Food Servers, } \\
\text { Cooks, Chefs) }\end{array}$}} & \multirow{2}{*}{\multicolumn{2}{|c|}{$\begin{array}{l}\text { (6) } \\
\text { Other general } \\
\text { unskilled } \\
\text { positions }\end{array}$}} \\
\hline & & & & & & & & & & & & \\
\hline & (A) & (B) & (A) & (B) & (A) & (B) & (A) & (B) & (A) & (B) & (A) & (B) \\
\hline \multirow[t]{2}{*}{ Attractive } & 0.017 & 0.011 & 0.024 & 0.005 & 0.032 & 0.030 & $0.075^{*}$ & $0.109 * *$ & $0.043^{*}$ & $0.067^{*}$ & 0.029 & 0.016 \\
\hline & $(0.010)$ & $(0.015)$ & $(0.024)$ & $(0.026)$ & $(0.036)$ & $(0.051)$ & $(0.038)$ & $(0.053)$ & $(0.022)$ & $(0.036)$ & $(0.019)$ & $(0.022)$ \\
\hline \multirow[t]{2}{*}{ No Photo } & 0.022 & 0.023 & -0.274 & -0.277 & 0.027 & 0.026 & 0.029 & 0.031 & 0.014 & 0.014 & -0.027 & -0.027 \\
\hline & $(0.014)$ & $(0.014)$ & $(0.024)$ & $(0.024)$ & $(0.037)$ & $(0.038)$ & $(0.028)$ & $(0.028)$ & $(0.025)$ & $(0.025)$ & $(0.019)$ & $(0.019)$ \\
\hline Attractive & - & 0.012 & - & 0.037 & - & 0.001 & - & $-0.080 *$ & - & -0.035 & - & 0.023 \\
\hline x Male & - & (0.018) & - & $(0.026)$ & - & $(0.030)$ & - & $(0.041)$ & - & $(0.033)$ & - & $(0.033)$ \\
\hline \multirow[t]{2}{*}{ Constant } & 0.016 & 0.013 & -0.048 & -0.051 & 0.814 & 0.797 & 0.261 & 0.356 & -0.141 & -0.145 & 0.295 & 0.310 \\
\hline & $(0.130)$ & $(0.131)$ & $(0.368)$ & (0.369) & $(0.953)$ & $(0.953)$ & (0.199) & $(0.201)$ & $(0.183)$ & $(0.182)$ & $(0.229)$ & $(0.220)$ \\
\hline N. of Obs. & \multicolumn{2}{|c|}{$\frac{1}{674}$} & \multicolumn{2}{|c|}{681} & \multicolumn{2}{|c|}{402} & \multicolumn{2}{|c|}{230} & \multicolumn{2}{|c|}{351} & \multicolumn{2}{|c|}{201} \\
\hline
\end{tabular}

Notes: The classification of occupational categories follows the Standard Occupational Classification. (SOC, see http://www.bls.gov/oes/current/oes_stru.htm\#43-0000). Standard errors clustered at the employer level in parentheses. Controls include Age, Male, Married, and Photo Required. All models are estimated by OLS. *, **, and *** denote the 10,5 , and 1 percent significance level, respectively. 
Table 5. Results using an alternative measure of beauty

\begin{tabular}{|c|c|c|c|}
\hline & \multicolumn{3}{|c|}{ Dependent variable: Callback } \\
\hline & (1) & (2) & (3) \\
\hline (ln) Length Ratio & $-0.283^{* * *}$ & & -0.126 \\
\hline & $(0.098)$ & & $(0.183)$ \\
\hline \multirow[t]{2}{*}{ (ln) Width Ratio } & & $-0.1703^{* * *}$ & -0.117 \\
\hline & & $(0.048)$ & $(0.094)$ \\
\hline F-statistic for the joint & & & 6.74 \\
\hline hypothesis of no effects & & & $\{0.001\}$ \\
\hline of beauty on callbacks & & & \\
\hline$\{\mathrm{p}$-value $\}$ & & & \\
\hline Observations & 1663 & 1663 & 1663 \\
\hline
\end{tabular}

Notes: The length ratio measures the vertical distances between eyes and mouth as a fraction of the total face length. The width ratio measures the inter-ocular distance as a fraction of the total face width. Both variables are in logs. Standard errors clustered at the employer level in parentheses (462 clusters). All models are estimated by OLS. Controls include Age, Male, and Married, and Photo Required. *, **, and *** denote the 10,5 , and 1 percent significance level, respectively. 
Table 6. Duration model - hazard ratios

\begin{tabular}{l|ccc}
\hline & \multicolumn{3}{|c}{ Dependent variable: Time until contact } \\
\hline & $(1)$ & $(2)$ & $(3)$ \\
\hline Attractive & $1.350^{* * *}$ & $1.383^{* * *}$ & $1.296^{* * *}$ \\
& $(0.100\}$ & $(0.123)$ & $(0.131)$ \\
No Photo & & 1.049 & 1.031 \\
& & $(0.124)$ & $(0.124)$ \\
\hline Controls & No & No & Yes \\
Observations & 2540 & 2540 & 2539 \\
\hline
\end{tabular}

Notes: Standard errors clustered at the employer level in parentheses (462 clusters). All models are estimated assuming a Weibull distribution. In model (1), the sample is restricted to resumes that include a photograph attached. Controls include Age, Male, Married, and Photo Required. Notice that the relevant null hypothesis is a hazard-ratio equal to one (as opposed to zero). *, **, and *** denote the 10 , 5 , and 1 percent significance level, respectively. 
Figure 1. Estimated survivor function by attractiveness

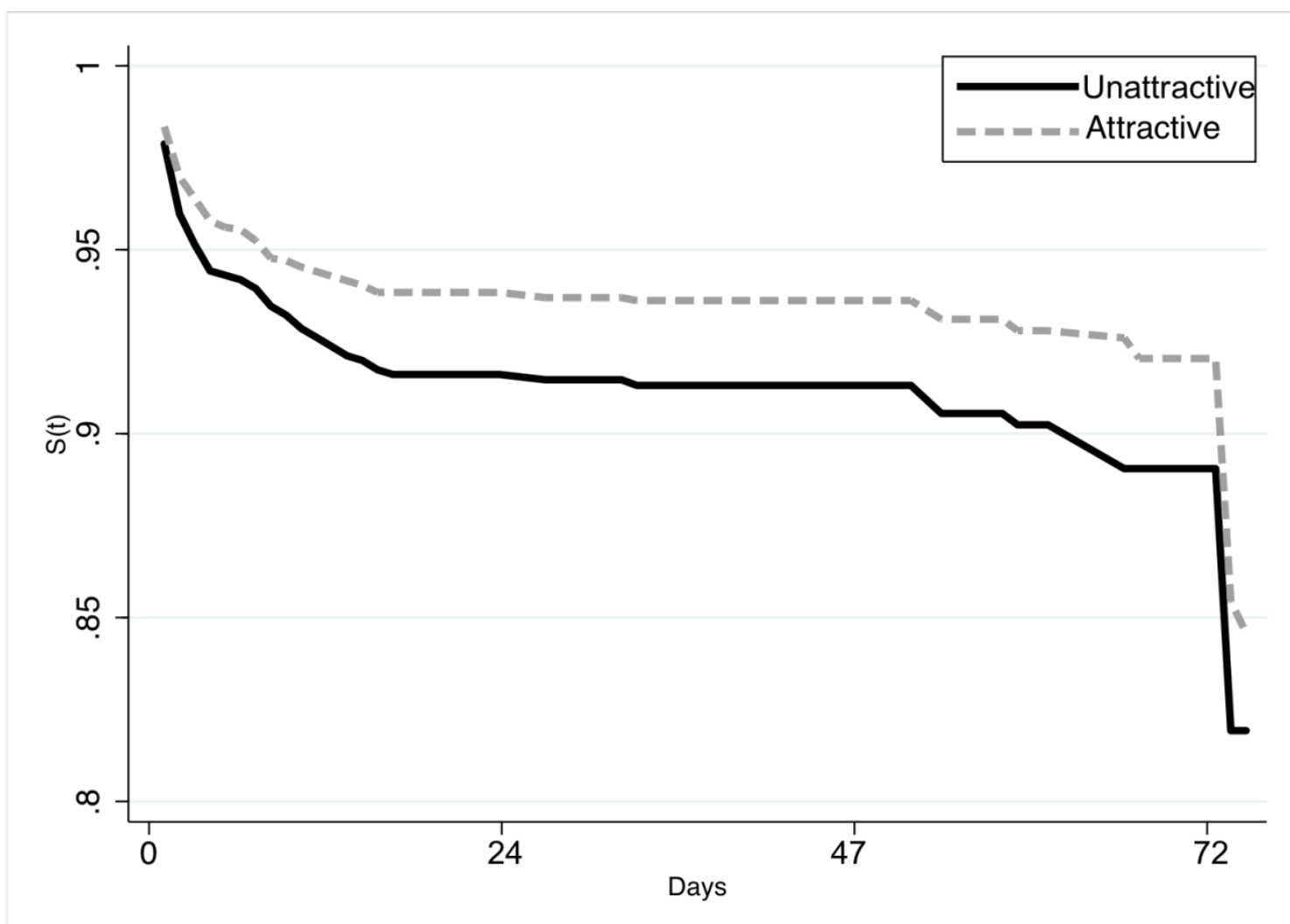

Note: The figure shows the duration model (survival model) for the analysis of the responsiveness to attractive faces. 


\section{Appendix 1. Construction of the photographs}

Fifty female faces and 50 male faces were photographed at Universidad de Buenos Aires. Full frontal photos of the faces were taken against a white or light blue background. A fictitious face was then generated from the mixture of two real faces. This process was done in four steps.

In the first step, two pictures of two individuals of the same gender were randomly chosen to be mixed and to generate a new face. The photos were selected because the size and position of the head of the two individuals was similar. This process was done using Adobe Photoshop. Once the modification was made, the two new generated pictures were saved in .jpg format.

In the second step, Morph Age Pro software was used to generate the new fictitious face. We generate a new file by importing the two photos in .jpg format. The Morph Age Pro software mixes the two pictures like in an animation. It creates a sequence of new photos from the mixture, where the two real/original pictures are located in each of the extremes of this sequence. The image situated in the middle of the sequence is an image that contains 50 percent of each original picture. To make the mixture as realistic as possible, the Cartesian position of each element of the face (eyes, mouth, nose, hair, etc.) must be the same between the two photos. This was done using a vector technique built into the software. Two different procedures were chosen to establish the hair colour and type and the clothes of the new fictitious person. In the first procedure, these characteristics were treated the same way the faces had been treated: that is, by overlapping the elements in the same Cartesian position. This procedure was used only in the cases when the clothes and the hair of the original pictures had a morphological similarity. If this was not the case, the second alternative was to directly copy the original clothes and hair from one of the two original pictures.

In the third step, and using Adobe Photoshop, the new file was opened to make the necessary corrections to make the pictures as realistic as possible. The skin tone and contours of the faces were corrected, a "blur' filter was applied, and the background of the picture was levelled. ${ }^{22}$

In the fourth step, the Adobe Photoshop and Morph Age Pro software were used again to emphasize the attractiveness (or lack of it) of the face, modifying the eye-to-

\footnotetext{
${ }^{22}$ A blur consists on placing a lens out of it focus point. It is done in order to erase every imperfection resulting from the overlap of the two faces.
} 
eye and eye-to-mouth distance with Cartesian vectors embedded in the software's program. The two softwares used the "golden ratios"” as defined in the text (eyemouth/face length $=36$ percent, and inter-ocular distance/face width $=46$ percent) to generate progressively less attractive or more attractive photos. Those ratios are found to optimize facial attractiveness. ${ }^{23}$ From each picture obtained in the last step, two new faces were generated.

Table A1 presents examples of this process. The first and second columns correspond to the same fictitious face, with the average (or "golden ratio") and nonaverage distances, respectively. To provide the reader with an example of the actual comparison that the employer evaluating the resumes will be making, we have added two columns. In the third column, we present a face with the average (or "golden ratio) distance (the attractive face). In the fourth column, we present a (different) fictitious face with non-average distance (the unattractive face).

\footnotetext{
${ }^{23}$ See Pallet, Link and Lee (2010) on how these ratios matter for the perceptions of beauty.
} 
Table A1. Attractiveness Criteria of the Photos Sent to Employers

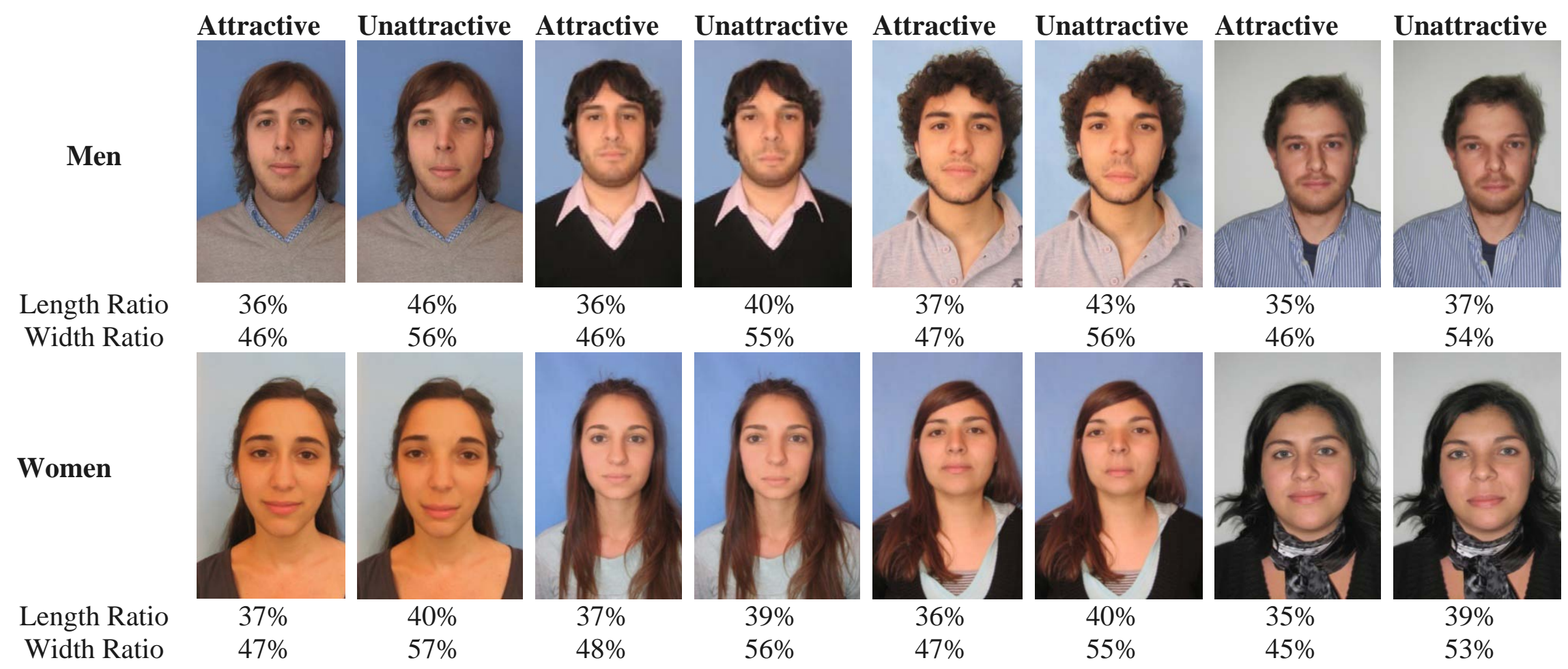

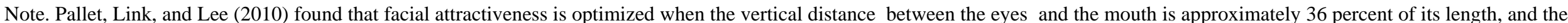
horizontal distance between the eyes is approximately 46 percent of the face's width. See text for further details. 
Table A2. Summary statistics for length and width ratios

\begin{tabular}{c|c|c|c} 
Variable & $\begin{array}{c}\text { Full } \\
\text { Sample }\end{array}$ & Attractive & Unattractive \\
\hline $\begin{array}{c}\text { Length ratio } \\
\text { (Vertical distance } \\
\text { between eyes and } \\
\text { mouth/ Total face } \\
\text { length) }\end{array}$ & 0.387 & 0.368 & 0.406 \\
{$[0.33-0.44]$} & {$[0.025)$} & $(0.015)$ & $(0.016)$ \\
\hline $\begin{array}{c}\text { Width Ratio } \\
\text { (Horizontal distance }\end{array}$ & 0.54 & 0.492 & 0.588 \\
$\begin{array}{c}\text { between eyes/ Total } \\
\text { face width) }\end{array}$ & $(0.055)$ & $(0.022)$ & $(0.03)$ \\
\hline
\end{tabular}

Note: the average width ratio for the attractive candidates is 3 percentage points higher than the "golden ratio" (0.46). This is due to the fact that we barely modified the picture results of the blending of the two original pictures. We took those "average faces" as the "attractive faces" without further modifications, which left us with a slightly higher width ratio for the attractive candidates. 